\section{USE OF PLACEBO: KNOWLEDGE, ATTITUDE AND PRACTICE AMONG MEDICAL PRACTITIONERS}

Sir,

The use of placebo is not confined to clinical trials but has also extended to routine clinical practice. ${ }^{[1]}$ Literature search revealed a few studies related to the use of placebo in therapy. ${ }^{[2,3]}$ The present study was undertaken to evaluate the practice and pattern of use of placebo among medical practitioners and their knowledge and attitude regarding placebo.

The study was carried out in Ahmedabad city and included specialists and resident doctors of a teaching hospital, as well as general practitioners (GPs). A questionnaire prepared based on earlier study ${ }^{[2]}$ was validated. The 3 groups of prescribers (30 in each group) were personally approached. A maximum of 2 visits were made at an interval of 1 week for collecting the questionnaire. Statistical analysis was carried out using SPSS version 15 . $P<0.05$ was considered statistically significant.

All 90 practitioners (male- 83, female- 7) returned the questionnaires. Their mean age was 35.2 years (24 to 59 years). Figure 1 shows the frequency of placebo use. There was no significant difference among the 3 groups $(P=$ 0.18).

The situations for placebo use were as follows: for nonspecific symptoms- $61.1 \%$; as a supplement to main therapy- $40 \%$; as a diagnostic tool$32.2 \%$; to calm a patient- $33.3 \%$; to satisfy/ mollify a patient- $23.3 \%$; to control pain- $23.3 \%$; instead of medicine, when using medicine is not justified$8.9 \%$; and instead of medicine in order to buy time between two doses of medicine- $5.6 \%$.
Placebo medications reported were as follows: vitamin tablets- $74 \%$; oral analgesics- $39 \%$; antacids- 15\%; and injection of distilled water, normal saline or multivitamins- $12 \%$.

Of the 80 placebo prescribers, $48(60 \%)$ labeled it as "medicine." Resident doctors did it more frequently than GPs $(P<0.05)$. Of the rest, $39 \%$ revealed nothing to the patients, while 1 GP revealed that it was a placebo. Regarding effectiveness of placebo, $90 \%(72 / 80)$ of the prescribers believed that placebo is usually/ sometimes effective. Three groups did not differ significantly.

Regarding appropriateness of prescribing placebo, $57.8 \%$ believed it should be used by experienced hands or when there is evidence of efficacy in a given situation, $14.4 \%$ favored use for research purpose and $24.5 \%$ believed it may be tried in selected situations without previous experience. Only $3.3 \%$ of the doctors believed that placebo should never be used.

Practitioners' knowledge regarding mechanism of placebo effect has been depicted in Figure 2. About $75 \%$ (68/90) of the practitioners opined in favor of psychological mechanism for

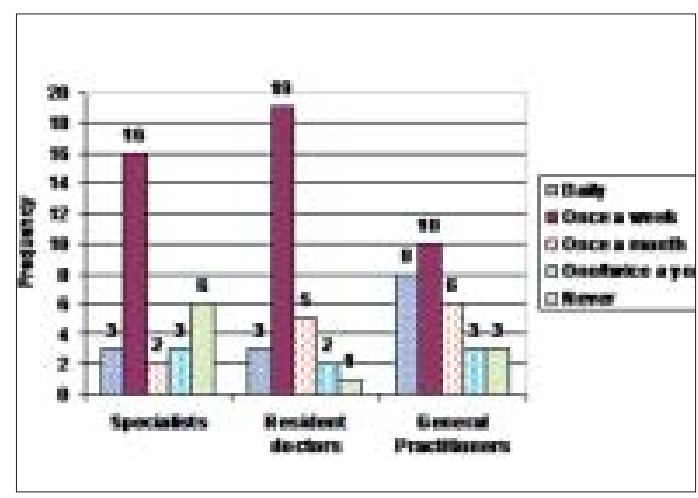

Figure 1: Frequency of prescribing placebo $(n=30$ in each group) 


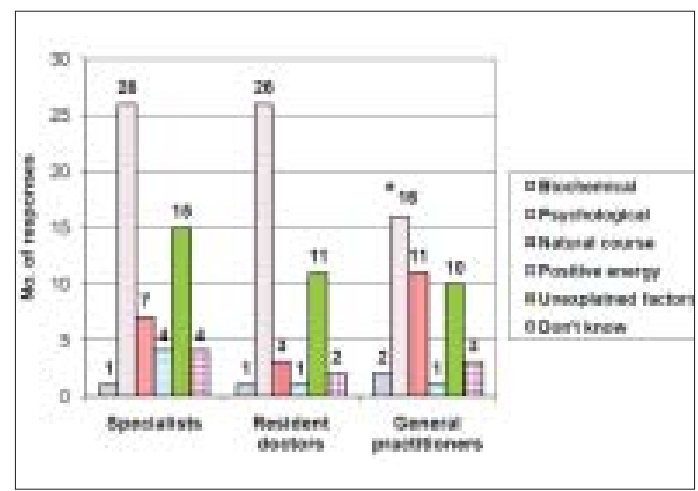

Figure 2: Practitioners' knowledge regarding mechanism of placebo effect ( $n=30$ in each group) ${ }^{*}$ chi-square test general practitioners differed significantly from specialists and resident doctors $(\mathrm{P}<.02)$

placebo response. Both the specialists and the residents differed significantly from the general practitioners $(P<0.02)$.

A survey of GPs reported $86 \%$ prevalence of use of placebo at least once within the past year, and $48 \%$ using placebo treatments more than 10 times in the past year. ${ }^{[4]}$ Another study reported $60 \%$ prevalence,,$^{[2]}$ a national survey of U.S. internists and rheumatologists showed $55 \%$ prevalence ${ }^{[3]}$ while a study of U.S. academic physicians reported $45 \%$ prevalence..$^{[5]}$ Our study showed higher (89\%) prevalence of placebo prescribing; and of these, $80 \%$ reported using it more than 10 times a year. With $27 \%$ of the GPs reporting daily use of placebo, this group seems to be the highest placebo user, possibly due to reasons like limited diagnostic skills, giving in to patients' demands, etc. Frequent use of placebo as a diagnostic tool (32.2\%), a finding consistent with that of an Israel study, ${ }^{[2]}$ can be potentially harmful to patients.

Our study also showed frequent use of vitamins and analgesics as placebo medicines. These findings are similar to those of U.S. studies. ${ }^{[3,5]}$ Only $9 \%$ reported use of saline and distilled water injections, showing a trend of preferential use of "impure" placebo over "pure" placebo. ${ }^{[1]}$

Limitations of this study are its small sample size and possible under-reporting by the practitioners. However, it can be certainly concluded that there is high prevalence of placebo use in clinical practice. Consistent with previous studies, ${ }^{[2,5]}$ this study also found that most of the doctors believed that the effect of placebo was attributable to a psychological mechanism.

KARTIK N. SHAH, DHAVAL J. PANCHAL, BHAVESH M. VYAS, VARSHA J. PATEL Department of Pharmacology, Smt. NHL Municipal Medical College, Ahmedabad, India

Correspondence: Dr. Kartik N. Shah, Department of Pharmacology, Smt. NHL Municipal Medical College, V. S. Hospital Campus, Ellisbridge, Ahmedabad - 380 006, Gujarat, India E-mail: drkns76@gmail.com

\section{REFERENCES}

1. Bourne HR. Rational use of placebo. In: Melmon $\mathrm{KL}$, Morrelli HF, editors. Clinical pharmacology: Basic principles in therapeutics. $2^{\text {nd }}$ ed. New York: MacMillan Publishing Co. Inc.; 1978. p. 1052-62.

2. Nitzan U, Lichtenberg P. Questionnaire survey on use of placebo. BMJ 2004;329:944-6.

3. Tilburt JC, Emanuel EJ, Kaptchuk TJ, Curlin FA, Miller FG. Prescribing "placebo treatments": Results of national survey of US internists and rheumatologists. BMJ 2008;337:1097-100.

4. Hrobjartsson A, Norup M. The use of placebo interventions in medical practice: A national questionnaire survey of Danish clinicians. Eval Health Prof 2003;26:153-65.

5. Sherman R, Hickner J. Academic physicians use placebos in clinical practice and believe in the mindbody connection. J Gen Intern Med 2008;23:7-10.

PMID: 19901489 